\title{
The complex relationship between inflammation and lung function in severe asthma
}

\author{
ML Manni ${ }^{1}$, JB Trudeau ${ }^{2}$, EV Scheller ${ }^{1}$, S Mandalapu $^{1}$, MM Elloso $^{3}$, JK Kolls ${ }^{4}$, SE Wenzel ${ }^{2}$ and JF Alcorn $^{1}$
}

Asthma is a common respiratory disease affecting $\sim 300$ million people worldwide. Airway inflammation is thought to contribute to asthma pathogenesis, but the direct relationship between inflammation and airway hyperresponsiveness (AHR) remains unclear. This study investigates the role of inflammation in a steroid-insensitive, severe allergic airway disease model and in severe asthmatics stratified by inflammatory profile. First, we used the T-helper $\left(T_{H}\right)-17$ cells adoptive transfer mouse model of asthma to induce pulmonary inflammation, which was lessened by tumor necrosis factor (TNF)- $\alpha$ neutralization or neutrophil depletion. Although decreased airspace inflammation following TNF $\alpha$ neutralization and neutrophil depletion rescued lung compliance, neither intervention improved AHR to methacholine, and tissue inflammation remained elevated when compared with control. Further, sputum samples were collected and analyzed from 41 severe asthmatics. In severe asthmatics with elevated levels of sputum neutrophils, but low levels of eosinophils, increased inflammatory markers did not correlate with worsened lung function. This subset of asthmatics also had significantly higher levels of $\mathrm{T}_{\mathrm{H}}$ 17-related cytokines in their sputum compared with severe asthmatics with other inflammatory phenotypes. Overall, this work suggests that lung compliance may be linked with cellular inflammation in the airspace, whereas T-cell-driven AHR may be associated with tissue inflammation and other pulmonary factors.

\section{INTRODUCTION}

Asthma is a complex heterogeneous disorder with a broad spectrum of phenotypes ranging from mild to severe disease with varying degrees of responsiveness to standard steroid therapy. Traditionally, asthma is viewed as an eosinophilic airway disorder, and research has focused on the role of T-helper $\left(\mathrm{T}_{\mathrm{H}}\right)-2$ cells and cytokines (interleukin (IL)-4, IL-5, and IL-13) in promoting these pathological features. Most patients with asthma have disease that can be well controlled with inhaled corticosteroids and long-acting $\beta 2$-agonists, but $\sim 5-10 \%$ of asthmatics have severe refractory disease. ${ }^{1-3}$ Severe asthma differs from mild or moderate persistent asthma, as it can often be characterized by neutrophilic inflammation in the presence or absence of classical $\mathrm{T}_{\mathrm{H}} 2$-induced eosinophilic inflammation. In addition, $\mathrm{T}_{\mathrm{H}} 17$ cells, which mediate neutrophil recruitment, are thought to have an influential role in asthma pathogenesis, especially in asthmatics that fail to respond to glucocorticoid therapy. ${ }^{4}$ However, the presence of this phenotype in patients is yet to be clearly defined.

Atopic asthma is thought to be driven by the recruitment of $\mathrm{CD}^{+}{ }^{+} \mathrm{T}$ lymphocytes to the lungs and is characterized by pulmonary inflammation, reversible airflow limitation, mucus hypersecretion, and airway hyperresponsiveness (AHR). However, the relationship between inflammation and physiological changes is complex. Several studies have shown that the extent of neutrophilia correlates to asthma severity. ${ }^{5-7}$ Indeed, it has been reported that subsets of asthmatics characterized by neutrophilic inflammation exhibit decreased improvement in $\mathrm{FEV}_{1}$ (forced expiratory volume in $1 \mathrm{~s}$ ) and AHR following glucocorticoid treatment. ${ }^{8}$ Furthermore, neutrophils are known to be largely steroid-insensitive and glucocorticoids inhibit neutrophil apoptosis. ${ }^{9,10}$ Although steroid-resistant asthma is often neutrophil dependent, ${ }^{11}$ lavage or biopsy eosinophils were also related to severe therapy-resistant asthma, and lung

${ }^{1}$ Division of Pulmonary Medicine, Allergy and Immunology, Department of Pediatrics, Children's Hospital of Pittsburgh of UPMC, Pittsburgh, Pennsylvania, USA. ${ }^{2}$ Division of Pulmonary, Allergy, and Critical Care Medicine, Department of Medicine, University of Pittsburgh Asthma Institute at UPMC/University of Pittsburgh School of Medicine, Pittsburgh, Pennsylvania, USA. ${ }^{3}$ Janssen Research and Development, Immunology Discovery Research, Spring House, Pennsylvania, USA and ${ }^{4}$ Richard King Mellon Foundation Institute for Pediatric Research, Department of Pediatrics, Children's Hospital of Pittsburgh of UPMC, Pittsburgh, Pennsylvania, USA. Correspondence: JFAlcorn (john.alcorn@chp.edu)

Received 5 August 2013; accepted 16 December 2013; published online 19 February 2014. doi:10.1038/mi.2014.8 
function changes in children and adults. ${ }^{12}$ Despite such correlative studies, the mechanistic role of airway inflammation in relation to AHR is currently unclear. We therefore investigated the inflammatory phenotype of severe asthma and the involvement of inflammation in the physiological changes in the lung.

\section{RESULTS \\ Pulmonary inflammation is suppressed by anti-tumor necrosis factor- $\alpha$ treatment in $\mathrm{T}_{\mathrm{H}} 17$ cell transfer, ovalbumin-challenged mice}

The pro-inflammatory cytokine, tumor necrosis factor (TNF)$\alpha$, is thought to have an important role in the pathogenesis of asthma. To date, studies have mainly focused on the role of $\mathrm{TNF} \alpha$ in $\mathrm{T}_{\mathrm{H}}$ 2-based, eosinophil-dominant, steroid-sensitive asthma and little is known about its role in $\mathrm{T}_{\mathrm{H}} 17$-induced, neutrophil-dominant, steroid-resistant disease. Evidence supports a role for TNF $\alpha$ in severe asthma, as systemic and lung levels of TNF $\alpha$ are increased in patients with severe refractory asthma. ${ }^{13,14} \mathrm{TNF} \alpha$ is also known to synergize with IL-17A in a number of inflammatory models. Specifically, IL-17A is thought to contribute to asthma pathogenesis by influencing neutrophil influx into the lungs and airway remodeling, which are more prominent in chronic steroid-resistant disease. ${ }^{15}$ To determine whether TNF $\alpha$ or IL-17A mediates airway inflammation and AHR in $T_{H} 17$-dependent allergic airway disease, an adoptive transfer model of airway antigen-induced inflammation was used. $^{4}$ (Figure 1a) Briefly, in vitro-polarized $\mathrm{T}_{\mathrm{H}} 17$ cells were adoptively transferred into $\mathrm{BALB} / \mathrm{c}$ SCID mice that were challenged with ovalbumin (OVA) intratracheally 1 day before adoptive transfer and then again challenged with OVA following cell transfer for 3 consecutive days. Mice were also treated with anti-TNF $\alpha$, anti-IL-17A, or IgG1 control on days 1 and 3. Control mice did not receive T-cell transfer, but were challenged with OVA (no cell control). Other control groups included mice that received phosphate-buffered saline (PBS) intratracheally instead of OVA and IgG1 (PBS + IgG) or anti$\mathrm{TNF} \alpha(\mathrm{PBS}+$ anti-TNF $\alpha)$, as well as naive BALB/c SCID mice. Twenty-four hours after the last OVA challenge, $T_{H} 17$-induced allergic airway responses were assessed (Figure 1a). This model was chosen to mimic the high neutrophil, low eosinophil allergic airway disease identified from stratification of severe asthmatics.

As expected, adoptive transfer of $\mathrm{T}_{\mathrm{H}} 17$ cells into OVAchallenged BALB/c SCID mice resulted in increased inflammatory cell recruitment into the lungs (Figure 1b). Differential counting of the bronchoalveolar lavage (BAL) fluid cells revealed that predominantly neutrophils and macrophages were elevated in $\mathrm{T}_{\mathrm{H}} 17$ cell transfer, OVA-challenged mice when compared with control mice (Figure 1c). This $\mathrm{T}_{\mathrm{H}} 17$-induced cell influx was markedly attenuated by anti-TNF $\alpha$ treatment, but not significantly reduced by anti-IL-17A treatment (Figure 1b). Specifically, anti-TNF $\alpha$ treatment following $\mathrm{T}_{\mathrm{H}} 17$ cell transfer and OVA challenge reduced the number of neutrophils in the airspaces, but had no effect on the number of macrophages (Figure 1c). Anti-IL-17A treatment slightly decreased the number of neutrophils and increased macrophages present in the airspaces when compared with $\mathrm{T}_{\mathrm{H}} 17$ cell transfer, OVA-challenged mice (Figure 1c). Histological analyses of the lung also confirmed that cellular inflammation was significantly increased in the lung tissue of $\mathrm{T}_{\mathrm{H}} 17$ cell transfer, OVA-challenged mice when compared with OVAchallenged mice that did not receive $\mathrm{T}_{\mathrm{H}} 17$ cell transfer (no cell control). Further, both anti-TNF $\alpha$ and anti-IL-17A treatments significantly lessened tissue inflammation when compared with $\mathrm{T}_{\mathrm{H}} 17$ cell transfer, OVA-challenged mice. However, the amount of tissue inflammation present in the lungs of $\mathrm{T}_{\mathrm{H}} 17 \mathrm{cell}$ transfer, OVA-challenged mice treated with anti-TNF $\alpha$ and anti-IL-17A was still significantly increased above control levels (Figure 1d,e). Tissue inflammation was further characterized based on the location in the pulmonary tissue as perivascular-, peribronchial-, or parenchymalassociated inflammation (Supplementary Figure 1 online). Perivascular-, peribronchial-, and parenchymal-associated inflammation was higher in $\mathrm{T}_{\mathrm{H}} 17$ cell transferred, OVAchallenged mice regardless of antibody treatment when compared with all control mice (naive, PBS + IgG, PBS + anti-TNF $\alpha$, and no cell control mice). Further, OVA challenge alone induced tissue inflammation above control levels in BALB/c SCID mice (Supplementary Figure 1). Anti-TNF $\alpha$ treatment significantly reduced tissue inflammation in all three compartments, whereas anti-IL-17A treatment only reduced perivascular inflammation vs. $\mathrm{T}_{\mathrm{H}} 17$-transferred control mice. Overall, although airspace inflammation was significantly lessened by anti-TNF $\alpha$ treatment in $\mathrm{T}_{\mathrm{H}} 17$ cell transfer, OVA-challenged mice, a significant amount of tissue inflammation remained.

\section{Neutralization of TNF $\alpha$ markedly attenuates $T_{H} 17$-induced cytokine production in the lung}

To further characterize the inflammation observed in these mice, cytokine and chemokine levels in the lungs were measured. As expected, $\mathrm{T}_{\mathrm{H}} 17$ cell transfer, OVA-challenged mice expressed elevated levels of two primary $\mathrm{T}_{\mathrm{H}} 17$ cytokines, IL-17A ( $0.3 \pm 0.3$ vs. $68.4 \pm 19.9)$ and IL-22 (not detected vs. $56.5 \pm 20.8$ ), when compared with no cell controls. OVAchallenged mice reconstituted with $\mathrm{T}_{\mathrm{H}} 17$ cells showed increased levels of $\mathrm{T}_{\mathrm{H}} 1$ - (Figure 2a), $\mathrm{T}_{\mathrm{H}} 2$ - (Figure 2b), and $\mathrm{T}_{\mathrm{H}} 17$-related cytokines and chemokines (Figure 2c) in the lungs, whereas anti-TNF $\alpha$ and anti-IL-17A treatment in $\mathrm{T}_{\mathrm{H}} 17$ cell transfer, OVA-challenged mice significantly inhibited this response. Anti-TNF $\alpha$ treatment reduced cytokine levels to control levels for the majority of the cytokines measured, although some cytokines and chemokines increased or did not significantly change when compared with $\mathrm{T}_{\mathrm{H}} 17$ cell transfer, OVA-challenged mice (Supplementary Table 1). All control mice (naive, PBS + IgG, PBS + anti-TNF $\alpha$, and no cell control mice) had low levels of all cytokines and chemokines measured (Figure 2; Supplementary Table 1) except IL-13, IL-17A, IL-1 $\alpha$, and granulocyte-macrophage colony-stimulating factor (GM-CSF), which were induced by antibody treatment alone. As TNF $\alpha$ and IL-17A may regulate cytokine levels by impacting translation and secretion, we also examined the effect of antiTNF $\alpha$ and anti-IL-17A on cytokine mRNA levels (Figure 2d). 

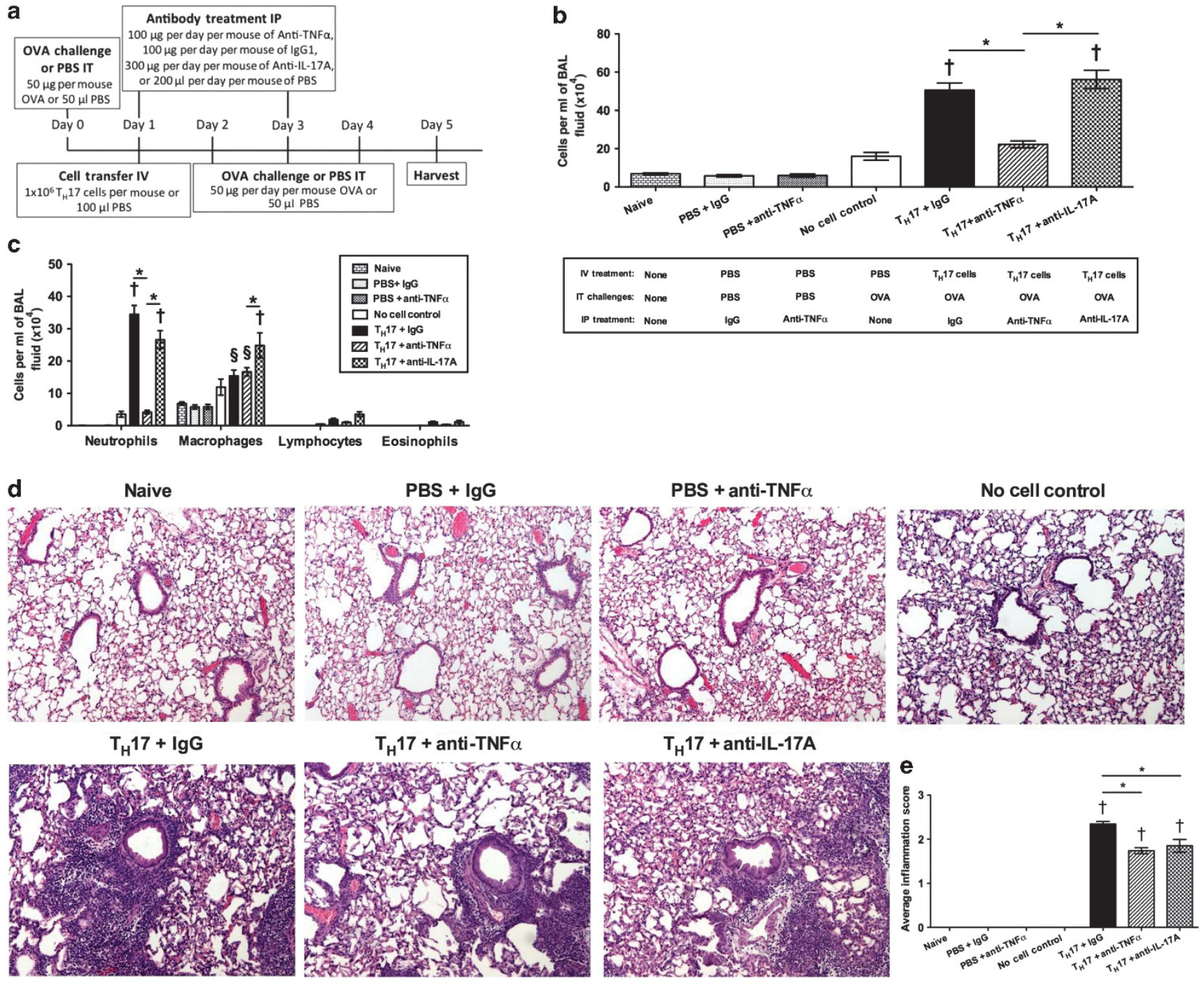

Figure 1 T-helper $\left(T_{H}\right)$-17-mediated airway inflammation is attenuated by tumor necrosis factor (TNF)- $\alpha$ neutralization in $T_{H} 17$ cell transfer, ovalbumin (OVA)-challenged mice. BALB/c SCID mice were treated as previously described to induce $T_{H} 17$-mediated allergic airway disease and treated with anti-TNF $\alpha$ or anti-IL-17A antibodies (a). Total cells per milliliter in the bronchoalveolar lavage (BAL) fluid (b), cell differentials (c), and hematoxylin and eosin-stained lung sections (d) were used to assess cellular inflammation in the lung. Cellular inflammation was also quantified by a pathologist (MLM) blinded to the groups (e). Mean \pm s.e.m., naive $(n=6)$, phosphate-buffered saline (PBS) $+\operatorname{lgG}(n=4)$, PBS + anti-TNF $\alpha(n=4)$, no cell control $(n=3)$, $\mathrm{T}_{\mathrm{H}} 17+\operatorname{IgG}(n=9-10), \mathrm{T}_{\mathrm{H}} 17+$ anti-TNF $\alpha(n=4-6), \mathrm{T}_{\mathrm{H}} 17+$ anti-IL-17A $(n=6)$, one-way ANOVA with Tukey's post-test (b,d) and two-way analysis of variance with the Bonferroni's post-test (c), ${ }^{\star} P<0.01$ for comparison is shown, ${ }^{\dagger} P<0.001$ when compared with all controls (naive, PBS + IgG, PBS + anti-TNF $\alpha$, and no cell control), ${ }^{\S} P<0.001$ when compared with naive, PBS $+\lg$, PBS + anti-TNF $\alpha$.

TNF $\alpha$ neutralization inhibited transcription of IL-4, IL-6, and interferon (IFN)- $\gamma$, whereas IL-17A antibody only impacted IL6 (Figure 2d). Overall, these results show that anti-TNF $\alpha$ attenuates protein and gene expression of many cytokines in the lungs of $\mathrm{T}_{\mathrm{H}} 17$ cell transfer, OVA-challenged mice. Anti-IL17A had lesser effects on the inflammatory cytokine milieu in the lungs of $\mathrm{T}_{\mathrm{H}} 17$ cell transfer, OVA-challenged mice when compared with anti-TNF $\alpha$.

\section{Lung compliance is restored, while AHR does not consistently change following anti-TNF $\alpha$ treatment in $T_{H} 17$ transfer, OVA-challenged mice}

Having observed that the neutralization of TNF $\alpha$ or IL-17A could alter pulmonary inflammation, we next wanted to determine whether anti-TNF $\alpha$ or anti-IL-17A treatment were sufficient to lessen AHR and mucus production in $T_{H} 17$ dependent allergic airway disease. $\mathrm{T}_{\mathrm{H}} 17$ cell transfer was found to significantly induce AHR above the levels found in control mice as expected based on previous findings ${ }^{4}$ (Figure 3a-e). Despite abrogating airspace inflammation and reducing tissue inflammation, AHR was not consistently altered in $\mathrm{T}_{\mathrm{H}} 17$ cell transfer, OVA-challenged mice following TNF $\alpha$ neutralization. $\mathrm{T}_{\mathrm{H}} 17$ cell transfer, OVA-challenged mice treated with anti$\mathrm{TNF} \alpha$ had significantly less airway resistance $(\mathrm{Rn})$ (Figure 3a), whereas greater tissue damping (G) (Figure 3b), when compared with $\mathrm{T}_{\mathrm{H}} 17$ cell transfer, OVA-challenged mice treated with IgG control. In addition, no change in lung elasticity $(\mathrm{H})$ between these groups was noted (Figure 3c). Although 

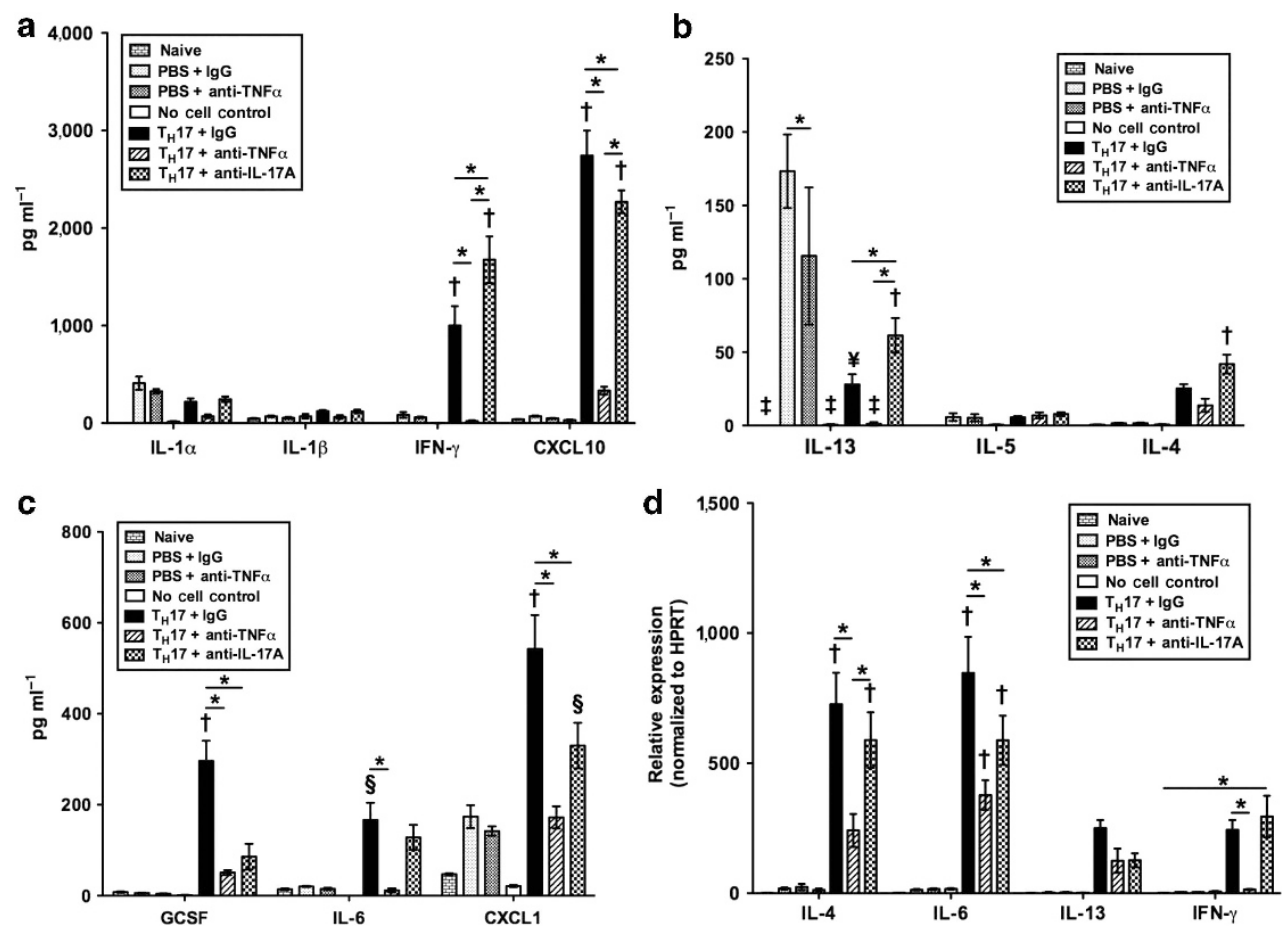

Figure 2 Cytokine and chemokine levels in the lung are attenuated by tumor necrosis factor (TNF)- $\alpha$ neutralization in T-helper ( $\left.T_{H}\right)$-17 cell transfer ovalbumin (OVA)-challenged mice. $\mathrm{T}_{\mathrm{H}} 1-(\mathbf{a}), \mathrm{T}_{\mathrm{H}} 2-(\mathbf{b})$, and $\mathrm{T}_{\mathrm{H}}$ 17-related (c) inflammatory cytokines/chemokines levels and mRNA expression (d) were also measured in the lung. Mean \pm s.e.m., naive $(n=5-6)$, phosphate-buffered saline (PBS) $+\operatorname{lgG}(n=4)$, PBS + anti-TNF $\alpha(n=4)$, no cell control $(n=3), \mathrm{T}_{\mathrm{H}} 17+\operatorname{IgG}(n=10), \mathrm{T}_{\mathrm{H}} 17+$ anti-TNF $\alpha(n=4-7), \mathrm{T}_{\mathrm{H}} 17+$ anti-IL-17A $(n=6),{ }^{*} P<0.05$ for comparison is shown, ${ }^{\dagger} P<0.05$ when compared with all controls (naive, PBS + IgG, PBS + anti-TNF $\alpha$, and no cell control), ${ }^{\S} P<0.05$ when compared with naive, PBS + anti-TNF $\alpha$, and no cell control, ${ }^{\ddagger} P<0.05$ when compared with PBS + IgG and PBS + anti-TNF $\alpha,{ }^{¥} P<0.05$ when compared with naive, PBS + IgG, and PBS + anti-TNF $\alpha$, two-way ANOVA with the Bonferroni's post-test.

anti-TNF $\alpha$ did not have a consistent effect on AHR, anti-TNF $\alpha$ did significantly improve static lung compliance and hysteresis (Figure 3d,e respectively). Anti-IL-17A treatment in $\mathrm{T}_{\mathrm{H}} 17$ cell transfer, OVA-challenged mice did not significantly change lung function when compared with $\mathrm{T}_{\mathrm{H}} 17$ cell transfer, OVAchallenged mice treated with IgG control (Figure 3a-e). Together, these data show that lung compliance (which is rescued by anti-TNF $\alpha$ ) may be linked with airspace cellular inflammation, whereas tissue inflammation may be one mechanism by which AHR is altered.

\section{Neutralization of TNF $\alpha$ and IL-17A increase mucus} hypersecretion in $\mathrm{T}_{\mathbf{H}} \mathbf{1 7}$ cell transfer, OVA-challenged mice Pulmonary expression of Clca3 (Figure 4a), Muc5ac (Figure 4b), and Muc5b (Figure 4c) was measured using real-time PCR, as these genes are associated with goblet cell hyperplasia and mucus production in allergic airway disease. ${ }^{16,17}$ Neutralization of TNF $\alpha$ significantly increased expression of $\mathrm{Muc5ac}$ and $\mathrm{Clca3}$, but not $\mathrm{Muc5b}$ in the lungs of $\mathrm{T}_{\mathrm{H}} 17$ cell transfer, OVA-challenged mice when compared with control mice. Neutralization of IL-17A in $\mathrm{T}_{\mathrm{H}} 17$ cell transfer, OVA-challenged mice also elevated clca 3 and mucin gene expression in the lungs when compared to $\mathrm{T}_{\mathrm{H}} 17$ cell transfer, OVA-challenged mice (Figure $\mathbf{4 a - c}$ ). Clca3 and Muc5ac expression were elevated to a lesser extent in $\mathrm{T}_{\mathrm{H}} 17$ cell transfer, OVA-challenged mice treated with anti-IL-17A than with anti-TNF $\alpha$, whereas $M u c 5 b$ expression was increased following IL-17A neutralization. Periodic acid-Schiff (PAS) staining of lung sections followed by histological scoring showed that increased mucus production was present in the lungs following neutralization of $\mathrm{TNF} \alpha$ in $\mathrm{T}_{\mathrm{H}} 17$-induced allergic airway disease (Figure 4d,e). Positive PAS staining was present in airway epithelial cells of all mice that received $\mathrm{T}_{\mathrm{H}} 17$ cell transfer, but not in the OVA-challenged control mice that did not receive a T-cell transfer, mice that received only IgG or anti-TNF $\alpha$ without T-cell transfer or OVA challenge, and naive BALB/c SCID mice. Overall, neutralization of TNF $\alpha$ significantly decreased neutrophilic inflammation, rescued lung compliance, and worsened mucus secretion, while having a small effect on AHR. Neutralization of IL-17A had lesser effects on inflammation, minimally impacted AHR, and worsened mucus secretion.

\section{Neutrophil depletion reduces $T_{H} 17$-induced pulmonary inflammation}

To determine whether the airway responses of $\mathrm{T}_{\mathrm{H}} 17$-reconstituted mice were mediated by neutrophils, BALB/c SCID mice were treated as outlined above. To selectively deplete neutrophils, mice were treated on days 1 and 3 during $\mathrm{T}_{\mathrm{H}} 17$ cell transfer and OVA challenge with an intraperitoneal injection of 

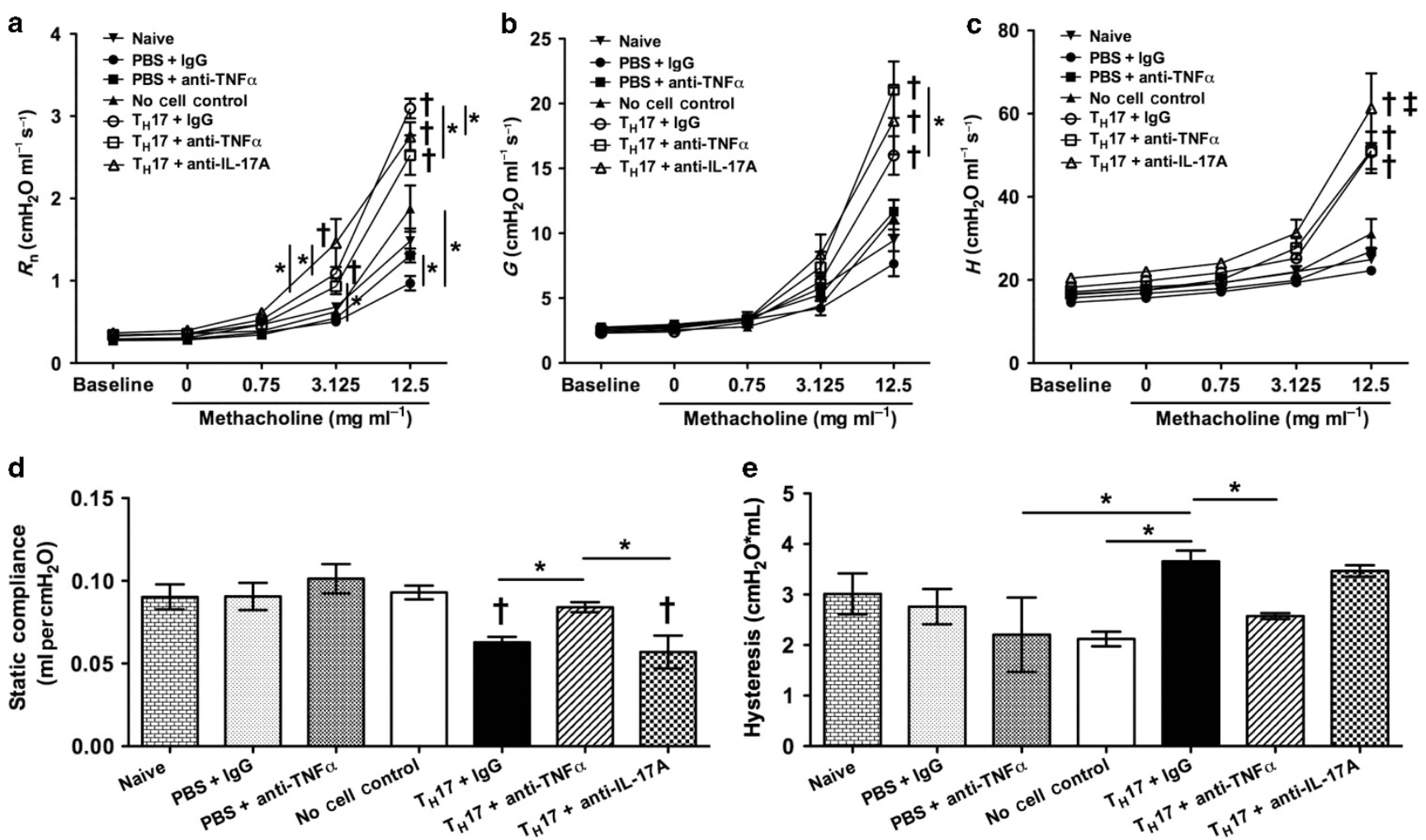

Figure 3 Tumor necrosis factor (TNF)- $\alpha$ neutralization rescues $T$-helper $\left(T_{H}\right)$-17-induced lung stiffening, but not airway hyperresponsiveness (AHR) in $\mathrm{T}_{\mathrm{H}} 17$ cell transfer, ovalbumin (OVA)-challenged mice. AHR to methacholine challenge (a-c) was evaluated in naive mice $(n=6)$, mice treated with phosphate-buffered saline (PBS) and IgG antibody $(n=4)$, mice treated with PBS and anti-TNF $\alpha$ antibody $(n=4)$, control mice with no cell transfer $(n=3)$, mice that received $\mathrm{T}_{\mathrm{H}} 17$ cells and IgG antibody $(n=12-14)$, mice that received $\mathrm{T}_{\mathrm{H}} 17$ cells and anti-TNF $\alpha$ antibody $(n=8-9)$, or mice that received $\mathrm{T}_{\mathrm{H}} 17$ cells and anti-IL-17A antibody $(n=5-6)$. Static lung compliance (d) and hysteresis (e) were also assessed in these mice. Mean \pm s.e.m., two-way ANOVA with the Bonferroni's post-test (a-c), and one-way ANOVA with the Tukey's post-test $(\mathbf{d}, \mathbf{e}),{ }^{\star} P<0.05$ for comparisons is shown, ${ }^{\dagger} P<0.05$ when compared with all controls (naive, PBS + IgG, PBS + anti-TNF $\alpha$, and no cell control), ${ }^{\ddagger} P<0.05$ when compared with $\mathrm{T}_{H} 17+\operatorname{lgG}$ and $\mathrm{T}_{\mathrm{H}} 17+$ antiTNF $\alpha$.

Ly6G-specific monoclonal antibody, 1A8 (Figure 5a). On day 5 , total cells in the BAL fluid and cell differentials were used to evaluate $\mathrm{T}_{\mathrm{H}}$ 17-induced cellular recruitment into the lungs (Figure 5a). Consistent with the present experiments and previous finding, ${ }^{4} \mathrm{~T}_{\mathrm{H}} 17$ cell transfer induced inflammatory cell influx into the lungs (Figure 5b), specifically neutrophils and macrophages (Figure 5c). As expected, the neutrophilic inflammation was significantly diminished with specific depletion using anti-Ly6G, 1A8 (Figure 5c). Histological analyses of the lungs also confirmed that treatment with $1 \mathrm{~A} 8$ decreased inflammation in $\mathrm{T}_{\mathrm{H}} 17$ cell transfer, OVA-challenged mice (Figure 5d-e). Tissue inflammation was further characterized based on the location in the pulmonary tissue as perivascular-, peribronchial-, or parenchymal-associated inflammation (Supplementary Figure 2). Perivascular-, peribronchial-, and parenchymal-associated inflammation was higher in $\mathrm{T}_{\mathrm{H}} 17$ cell transfer, OVA-challenged mice regardless of neutrophil depletion when compared with OVA-challenged mice that did not receive T-cell transfer (no cell control; Supplementary Figure 2). Neutrophil depletion significantly reduced peribronchial and parenchymal inflammation, but not perivascular inflammation.
Finally, neutrophil depletion lead to increased production of $\mathrm{T}_{\mathrm{H}} 17$ cytokines and chemokines (CXCL1, granulocyte colonystimulating factor (G-CSF), and IL-6, Figure 5f); as well as CXCL10 (Supplementary Table 2) in the lungs. TNF $\alpha$, CXCL2, CCL2, CCL3, CXCL5, GM-CSF, IFN- $\gamma$ IL-17A, IL13 , IL-10, IL-12p40, IL- $1 \alpha$, and IL- 4 were unchanged by neutrophil depletion in $\mathrm{T}_{\mathrm{H}} 17$ cell transfer, OVA-challenged mice (Supplementary Table 2). OVA-challenged mice that did not receive T-cell transfer (no cell control) had negligible or low levels of all cytokines and chemokines measured (Supplementary Table 2). These data show that neutrophil depletion alters the $\mathrm{T}_{\mathrm{H}} 17$-induced inflammatory milieu present in the lung.

\section{Neutrophil depletion rescues lung compliance, but not AHR, during $T_{H} 17$-induced allergic airway disease}

To determine whether neutrophils are necessary to induce $\mathrm{T}_{\mathrm{H}}$ 17-dependent AHR, AHR to methacholine was measured. $R_{n}$ and $G$ were found to be significantly decreased in $T_{H} 17$ cell transfer, OVA challenged, 1A8-treated mice when compared to mice that received $\mathrm{T}_{\mathrm{H}} 17$ cell transfer and OVA challenge (Figure 6a,b), although $\mathrm{T}_{\mathrm{H}} 17$ cell transfer and OVA challenge still induced AHR (vs. control mice, Figure 6a,b) in these mice. 

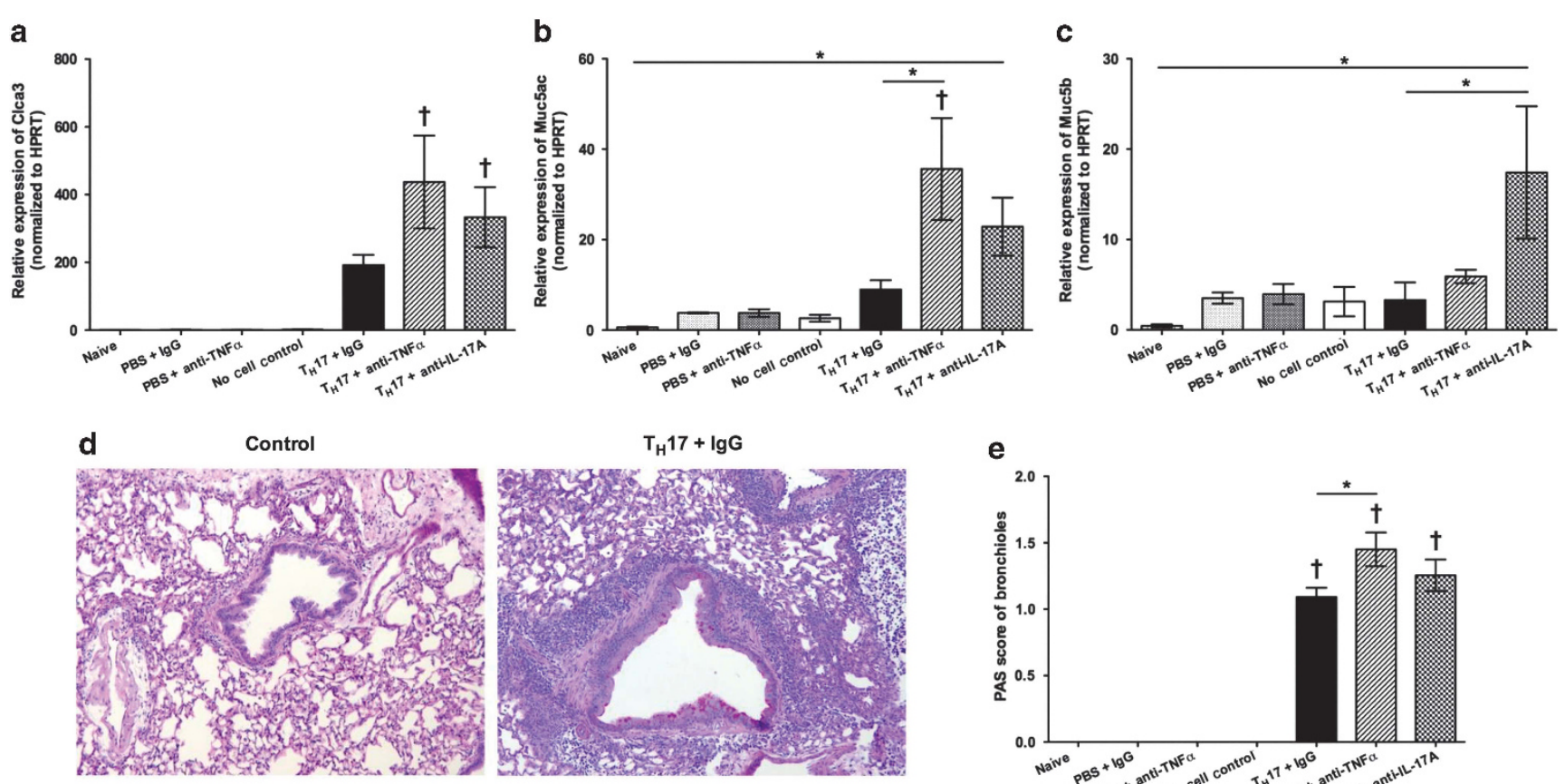

e

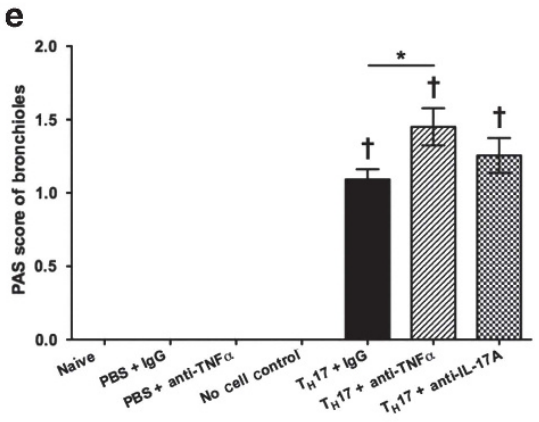

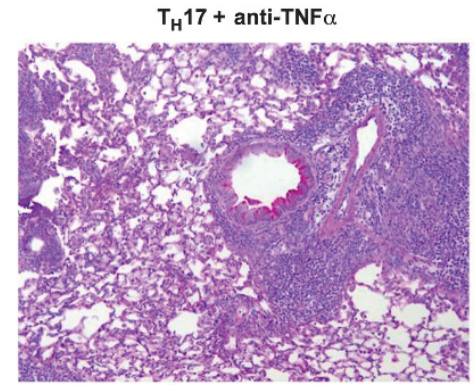

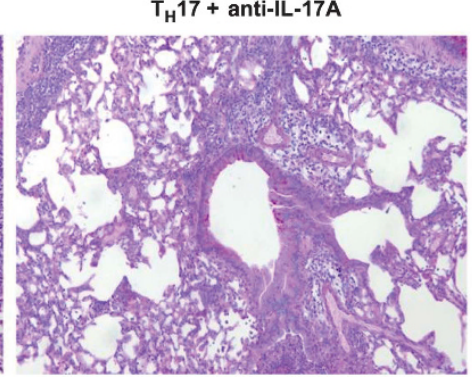

Figure 4 Mucus production induced by T-helper $\left(T_{H}\right)-17$ cell transfer and ovalbumin (OVA) challenge is worsened by tumor necrosis factor (TNF)- $\alpha$ neutralization in mice. Mucus production was assessed by real-time PCR for Clca3 (a), Muc5ac (b) Muc5b (c), and PAS staining of lung sections (d) following $T_{H} 17$ cell transfer with anti-TNF $\alpha$ or IgG treatment and following control treatments. Control shown is representative of all controls (naive, phosphate-buffered saline (PBS) + IgG, PBS + anti-TNF $\alpha$, and no cell control) (d). Mucus production was quantified by a pathologist (MLM) blinded to the groups (e). Mean \pm s.e.m., naive $(n=5-6)$, PBS $+\operatorname{IgG}(n=4)$, PBS + anti-TNF $\alpha(n=4)$, no cell control $(n=3), \mathrm{T}_{\mathrm{H}} 17+\operatorname{lgG}(n=10)$, $\mathrm{T}_{\mathrm{H}} 17+$ anti$\mathrm{TNF} \alpha(n=4-6), \mathrm{T}_{\mathrm{H}} 17+$ anti-IL-17A $(n=6)$, one-way ANOVA with the Tukey's post-test, ${ }^{\star} P<0.05$ for comparison is shown and ${ }^{\dagger} P<0.05$ when compared with all controls (naive, PBS + IgG, PBS + anti-TNF $\alpha$, and no cell control).

No significant changes were noted in $\mathrm{H}$ following $1 \mathrm{~A} 8$ treatment in $\mathrm{T}_{\mathrm{H}} 17$ cell transfer, OVA-challenged mice (Figure $\mathbf{6 c}$ ). In addition, neutrophils are partially responsible for lung stiffening in $\mathrm{T}_{\mathrm{H}}$ 17-dependent allergic airway disease, as neutrophil depletion trended to increase static lung compliance (Figure 6d) and decrease hysteresis (Figure 6e). Together, these data indicate that neutrophils have a partial role in the development of AHR in $\mathrm{T}_{\mathrm{H}}$ 17-dependent allergic airway disease.

\section{Depletion of neutrophils attenuates $T_{H} 17$-induced mucus production}

Pulmonary expression of Clca3 (Figure 7a), Muc5ac (Figure 7b), and Muc5b (Figure 7c) was measured using real-time PCR. $\mathrm{T}_{\mathrm{H}} 17$ cell adoptive transfer again increased mucus gene expression and PAS staining in BALB/c SCID mice. Neutrophil depletion significantly reduced mucus production in the lungs of $\mathrm{T}_{\mathrm{H}} 17$ cell transfer, OVA-challenged mice (Figure $7 \mathbf{a}-\mathbf{c}$ ). PAS staining of lung sections further confirmed this marked decrease in mucus production following depletion of neutrophils in $\mathrm{T}_{\mathrm{H}} 17$-induced allergic airway disease (Figure 7d,e). Positive PAS staining was present in airway epithelial cells of all mice that received $\mathrm{T}_{\mathrm{H}} 17$ cell transfer and OVA challenge, but not in the OVA-challenged control mice that did not receive a T-cell transfer. These data suggest that mucus production in this model may be dependent upon neutrophil products.

\section{Asthma subject characteristics}

As we have shown that AHR is present in a severe asthma model independent of neutrophilic inflammation in mice, we wanted to examine whether there is evidence for a subset of severe asthmatics that resembles this phenotype. Sputum samples were collected from 41 subjects with severe asthma, as defined by American Thoracic Society guidelines ${ }^{18}$ (Table 1). Severe asthmatics were stratified based on the percentage of neutrophils and eosinophils in the sputum using cutoffs of 


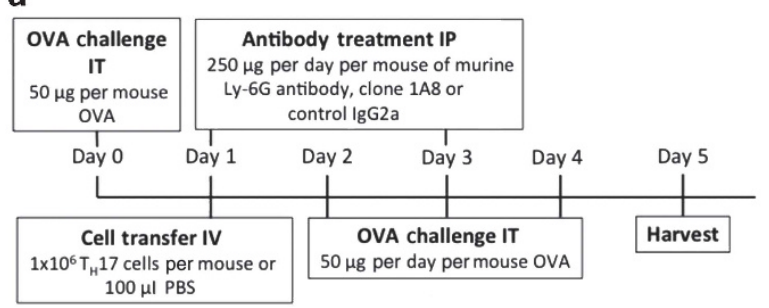

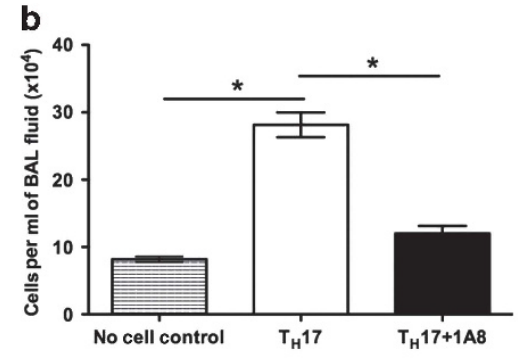

d
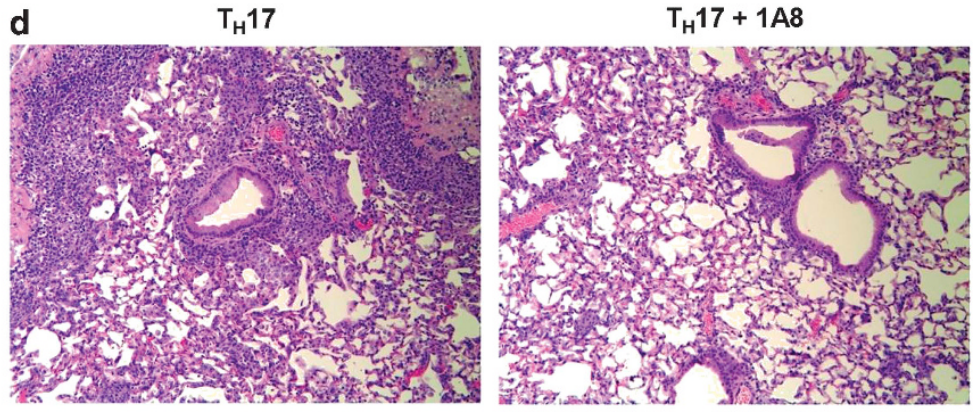

$\mathrm{T}_{\mathrm{H}} 17$ c

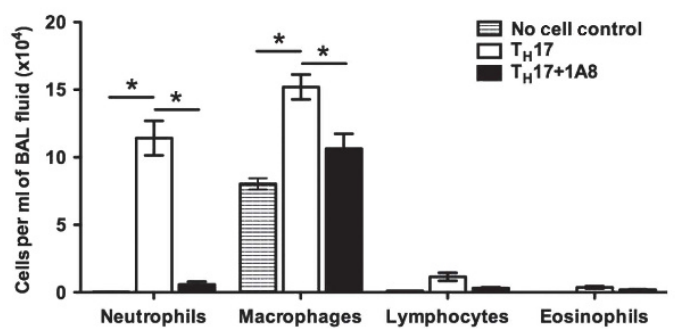

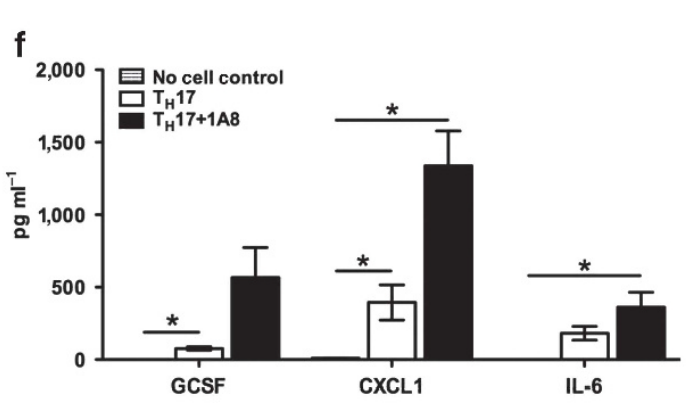

Figure 5 T-helper $\left(T_{H}\right)$-17-induced inflammatory responses are altered by neutrophil depletion by $1 \mathrm{~A} 8$ antibody. $T_{H} 17$-mediated allergic airway disease was induced in BALB/c SCID and neutrophils were depleted by $1 \mathrm{~A} 8$ antibody treatment as described in panel a. Total cells per milliliter in the bronchoalveolar lavage (BAL) fluid (b), cell differentials (c), and hematoxylin and eosin-stained lung sections (d) were used to assess cellular inflammation in the lung. Cellular inflammation was also quantified by a pathologist (MLM) blinded to the groups (e). $T_{H} 17$ cytokine and chemokine levels were measured using multiplex analyses (f). Control mice did not receive T-cell transfer, but were challenged with ovalbumin (OVA) (no cell control). Mean \pm s.e.m., $n=7-8$, two-way ANOVA with the Bonferroni's post-test $(\mathbf{c}, \mathbf{f})$ and one-way ANOVA with the Tukey's post-test $(\mathbf{b}, \mathbf{e}) ;{ }^{*} P<0.05$.

$>30 \%$ neutrophils or $1.8 \%$ eosinophils (based on University of Pittsburgh Severe Asthma Research Program site median splits) to designate "high" or "low" resulting in the following groups: patients with high levels of both neutrophils and eosinophils $(\mathrm{H} / \mathrm{H}, N=11)$, with high levels of neutrophils and low levels of eosinophils $(\mathrm{H} / \mathrm{L}, N=10)$, with low levels of neutrophils and high levels of eosinophils $(\mathrm{L} / \mathrm{H}, \mathrm{N}=11)$, and with low levels of both cell types (L/L, N=9). The groups did not differ by age, gender, race, age at onset, duration of symptoms, or body mass index. In regards to lung function, there were no significant differences in $\mathrm{FEV}_{1} \%$ predicted, forced vital capacity (FVC) $\%$ predicted, or $\mathrm{FEV}_{1} / \mathrm{FVC}$ between the groups of severe asthmatics. Use of corticosteroids did not differ between groups.

\section{Severe asthmatics with neutrophilia have a distinct inflammatory profile}

$\mathrm{T}_{\mathrm{H}} 17$ cells produce IL-17A, IL-17F, and IL-22, that have proinflammatory functions resulting in production of high levels of granulocyte and monocyte chemokines and growth factors, such as CXCL1, CCL2, IL-6, IL-8, and G-CSF. Cytokine levels in the sputum from the patient populations described above were examined to determine whether certain cytokines identified with these pre-specified cellular phenotypes in severe asthmatics. $\mathrm{H} / \mathrm{L}$ severe asthmatics had increased levels of CXCL1 (Figure 8a), CXCL10 (Figure 8b), CCL2 (Figure 8c), IL-6 (Figure 8d), and IL-8 (Figure 8e). Levels of G-CSF and IL-22 (Figure 8f,g) were not different among severe asthma groups, although $\mathrm{H} / \mathrm{L}$ severe asthmatics displayed a trend toward elevated IL-22 and G-CSF. There were no significant differences in sputum levels of CCL7, CCL3, CCL4, TNF $\alpha$, IL- $1 \alpha$, and IL-1 $\beta$ between groups (data not shown). Other cytokines and chemokines investigated included GM-CSF, IFN- $\alpha 2$, IFN- $\gamma$, IL-4, IL-5, IL-9, IL-10, IL-12p40, IL-13, IL-17A, and sCD40L, but amounts in the sputum were below the levels of detection for the majority of the samples collected (data not shown).

Sputum cytokine levels were then tested for correlation with pulmonary function (Table 2). Interestingly, sputum CXCL1 

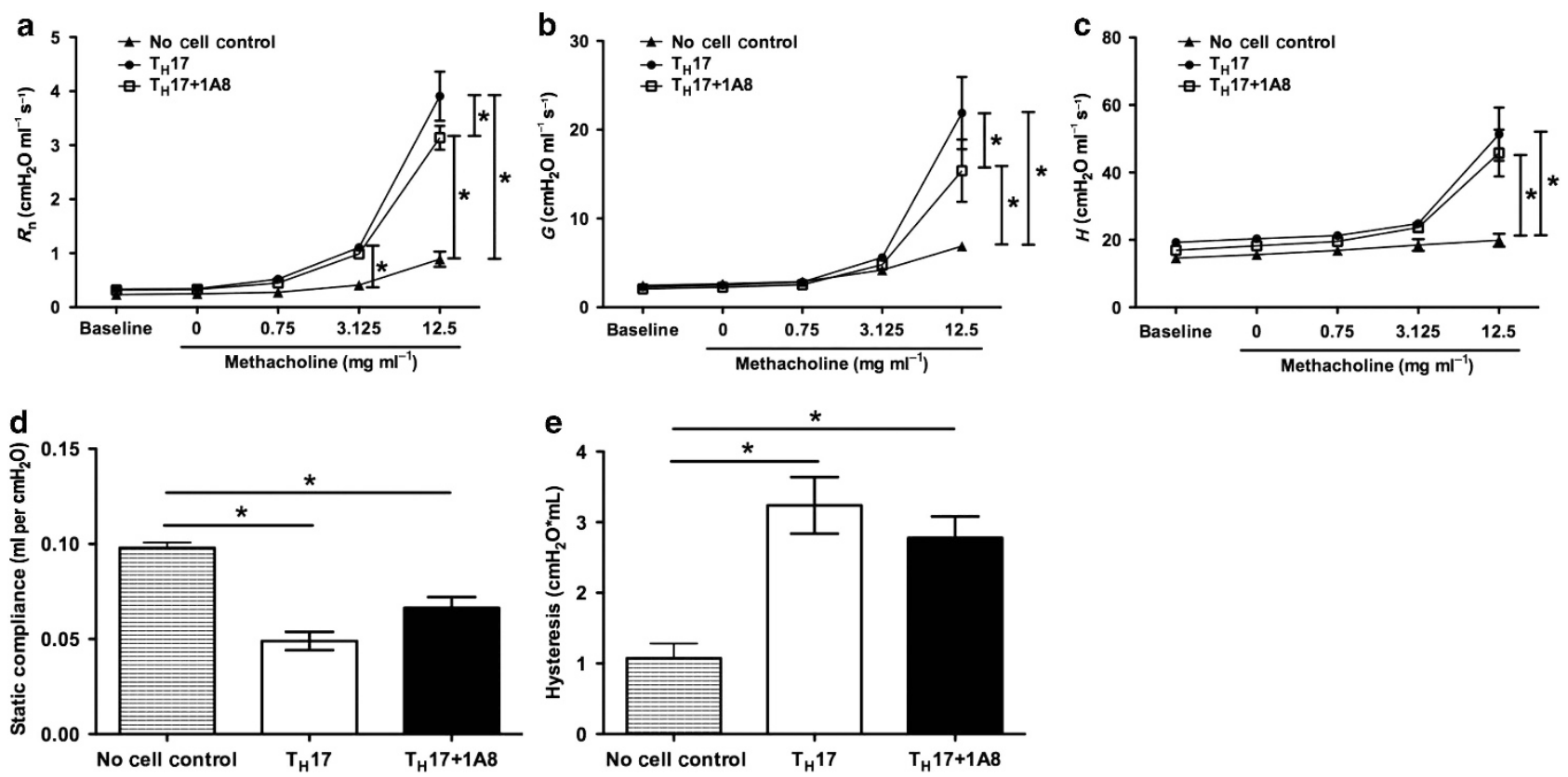

Figure 6 Neutrophil depletion rescues T-helper $\left(T_{H}\right)$-17-induced lung stiffening, but only partially affects airway hyperresponsiveness (AHR) in $T_{H} 17$ cell transfer, ovalbumin (OVA)-challenged mice. Dose response of methacholine in mice that received $T_{H} 17$ cells or mice that received $T_{H} 17$ cells treated with anti-Ly6G (1A8) antibody was determined using flexiVent analyses (a-c). Static lung compliance (d) and hysteresis (e) were also assessed in these mice. Mean \pm s.e.m., $n=7-8$, two-way ANOVA with the Bonferroni's post-test $(\mathbf{a}-\mathbf{c})$ and one-way ANOVA with the Tukey's post-test $(\mathbf{d}, \mathbf{e}) ;{ }^{*} P<0.05$.
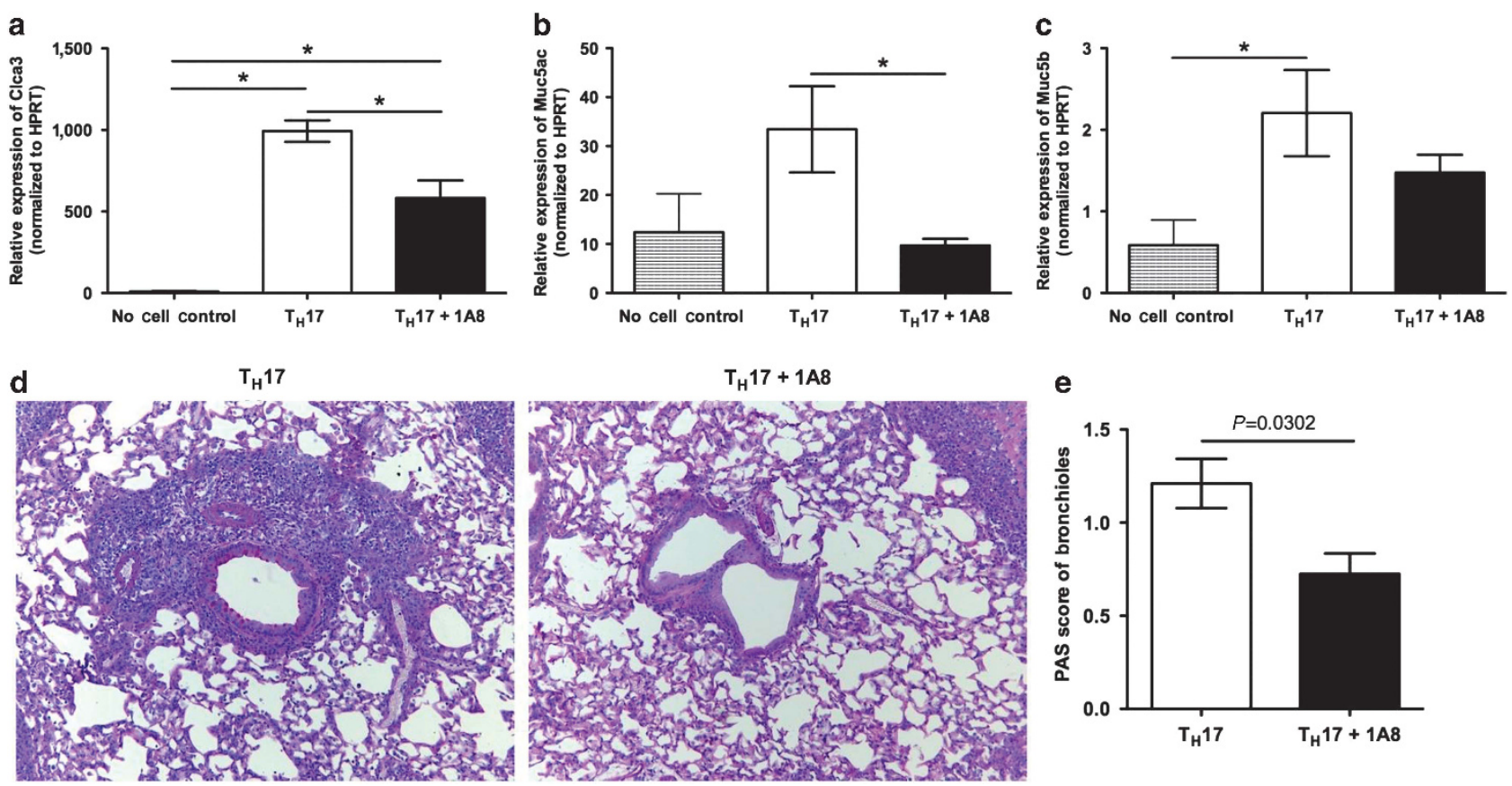

Figure 7 Neutrophil depletion by $1 \mathrm{~A} 8$ antibody decreases mucus production in T-helper $\left(\mathrm{T}_{\mathrm{H}}\right)$ - 17 cell transfer, ovalbumin (OVA)-challenged mice. Mucus production was assessed using real-time PCR for Clca3 (a), Muc5ac (b), and Muc5b (c) and PAS staining of lung sections (d). Mucus production was also quantified by a pathologist (M.L.M.) blinded to the groups (e). Mean \pm s.e.m., $n=6$-8/group except PAS quantification ( $n=4 /$ group), one-way ANOVA with Tukey's post-test $(\mathbf{a}-\mathbf{c})$, unpaired t-test $(\mathbf{e}),{ }^{\star} P<0.05$ unless otherwise noted.

levels $\left(r_{\mathrm{s}}=0.640, P=0.046\right)$ and IL-6 $\left(r_{\mathrm{s}}=0.766, P=0.01\right)$ were found to positively correlate to $\mathrm{FEV}_{1} \%$ predicted in the $\mathrm{H} / \mathrm{L}$ asthmatics. In addition, IL-6 was positively correlated with
$\mathrm{FEV}_{1} / \mathrm{FVC}\left(r_{\mathrm{s}}=0.733, P=0.02\right)$ in these patients. These data indicate that high cytokine inflammation correlate with improved lung function in $\mathrm{H} / \mathrm{L}$ asthmatics. Unlike $\mathrm{H} / \mathrm{L}$ 
Table 1 Subject characteristics

\begin{tabular}{|c|c|c|c|c|c|}
\hline & \multicolumn{4}{|c|}{ Severe asthmatics } & $P$ value \\
\hline$N=41$ & 11 & 10 & 11 & 9 & \\
\hline \multicolumn{6}{|l|}{ Gender } \\
\hline Male/female & $5 / 6$ & $3 / 7$ & $5 / 6$ & $4 / 5$ & 0.88 \\
\hline Caucasian/African American/Other & $9 / 2 / 0$ & $7 / 2 / 1$ & $8 / 3 / 0$ & $7 / 1 / 1$ & 0.93 \\
\hline Age (in years) & $34.6 \pm 4.9$ & $36.9 \pm 3.7$ & $43.0 \pm 5.8$ & $31.7 \pm 6.0$ & 0.47 \\
\hline Age at onset & $12.7 \pm 3.9$ & $11.8 \pm 5.7$ & $23.7 \pm 6.7$ & $10.9 \pm 6.5$ & 0.35 \\
\hline Duration & $21.8 \pm 5.5$ & $27.0 \pm 3.3 N=9$ & $19.3 \pm 3.9$ & $20.7 \pm 4.9$ & 0.68 \\
\hline $\mathrm{FEV}_{1} \%$ predicted & $56.3 \pm 7.5$ & $54.6 \pm 7.7$ & $68.9 \pm 7.0$ & $66.7 \pm 9.3$ & 0.47 \\
\hline FVC \% predicted & $76.3 \pm 7.7$ & $72.5 \pm 8.7$ & $80.3 \pm 6.9$ & $89.4 \pm 10.5$ & 0.56 \\
\hline $\mathrm{FEV}_{1} / \mathrm{FVC}$ & $0.6 \pm 0.04$ & $0.6 \pm 0.04$ & $0.7 \pm 0.03$ & $0.6 \pm 0.03$ & 0.19 \\
\hline \multicolumn{6}{|l|}{ Corticosteroid use (yes/no) } \\
\hline Inhaled & $11 / 0$ & $9 / 1$ & $10 / 1$ & $9 / 0$ & 0.60 \\
\hline Systemic & $8 / 3$ & $9 / 1$ & $5 / 6$ & $6 / 3$ & 0.19 \\
\hline
\end{tabular}

$\mathrm{BMI}$, body mass index; $\mathrm{FEV}_{1}$, forced expiratory volume in $1 \mathrm{~s} ; \mathrm{FVC}$, forced vital capacity.

Mean \pm s.e.m. are shown, and the number of subjects is indicated if information was not available for all subjects in the group.

asthmatics, poor lung function correlated with greater cytokine levels in all other severe asthmatic groups. Among $\mathrm{H} / \mathrm{H}$ asthmatics, IL- 8 inversely correlated with $\mathrm{FEV}_{1} \%$ predicted $\left(r_{\mathrm{s}}=-0.627, P=0.04\right)$ and FVC $\%$ predicted $\left(r_{\mathrm{s}}=-0.664\right.$, $P=0.03)$. CCL2 $\left(r_{\mathrm{s}}=-0.850, P=0.004\right)$ inversely correlated with $\mathrm{FEV}_{1} \%$ predicted and inversely correlated $\left(r_{\mathrm{s}}=-0.733\right.$, $P=0.03$ ) with FVC \% predicted in $\mathrm{L} / \mathrm{L}$ asthmatics. Finally, there were no significant correlations between lung function and sputum cytokine level in the $\mathrm{L} / \mathrm{H}$ asthmatics. These findings in severe asthmatics were similar to the murine studies in that cytokine levels for $\mathrm{H} / \mathrm{L}$ severe asthmatics did not predict declining lung function (in fact it was the opposite). Overall, in severe asthma that is characterized by high levels of neutrophils and low levels of eosinophil in the lungs, levels of inflammatory cytokines may not be indicative of poor lung function.

\section{DISCUSSION}

Asthma is a complex heterogeneous disorder with a broad spectrum of phenotypes ranging from mild to severe disease with varying degrees of responsiveness to standard steroid therapy. Severe asthmatics often have disease that does not involve canonical $\mathrm{T}_{\mathrm{H}} 2$ or eosinophilic inflammation and is not well controlled by conventional corticosteroids. Many studies have attempted to define phenotypes of severe asthma as reviewed by Wenzel. ${ }^{19}$ Unfortunately, these clinically characterized phenotypes provide little insight into the underlying pathogenic mechanisms of disease.

Much of the research in the field of allergic asthma has focused on $\mathrm{T}_{\mathrm{H}} 2$-dominant, eosinophilic disease. The murine model herein is a model of non-eosinophilic, steroid-insensitive asthma. ${ }^{4}$ In this model, adoptive transfer of OVA-specific $\mathrm{T}_{\mathrm{H}} 17$ cells to donor mice is sufficient to promote the hallmark characteristics of severe asthma in vivo, such as neutrophilic inflammation, AHR, and mucus metaplasia, which are not attenuated by glucocorticoid treatment. ${ }^{4}$ Current asthma models also involve antigen sensitization and subsequent antigen challenge for asthma development. As clinical presentation of disease is long after antigen sensitization and $\mathrm{T}$-cell polarization in humans, one cannot intervene in these stages of asthma development. Therefore, focusing on T-cell effector mechanisms may be the key to effective therapies and the need for animal models to investigate mechanisms of established asthma is evident. This innovative adoptive transfer model allows for antigen challenge responses to be investigated independent of antigen sensitization. Unlike existing methodologies, this model is instrumental in facilitating investigations into critical T-cell effector mechanisms and in allowing for experimental intervention at this stage.

Although the development of allergen-induced airway inflammation has been extensively studied, few studies have 

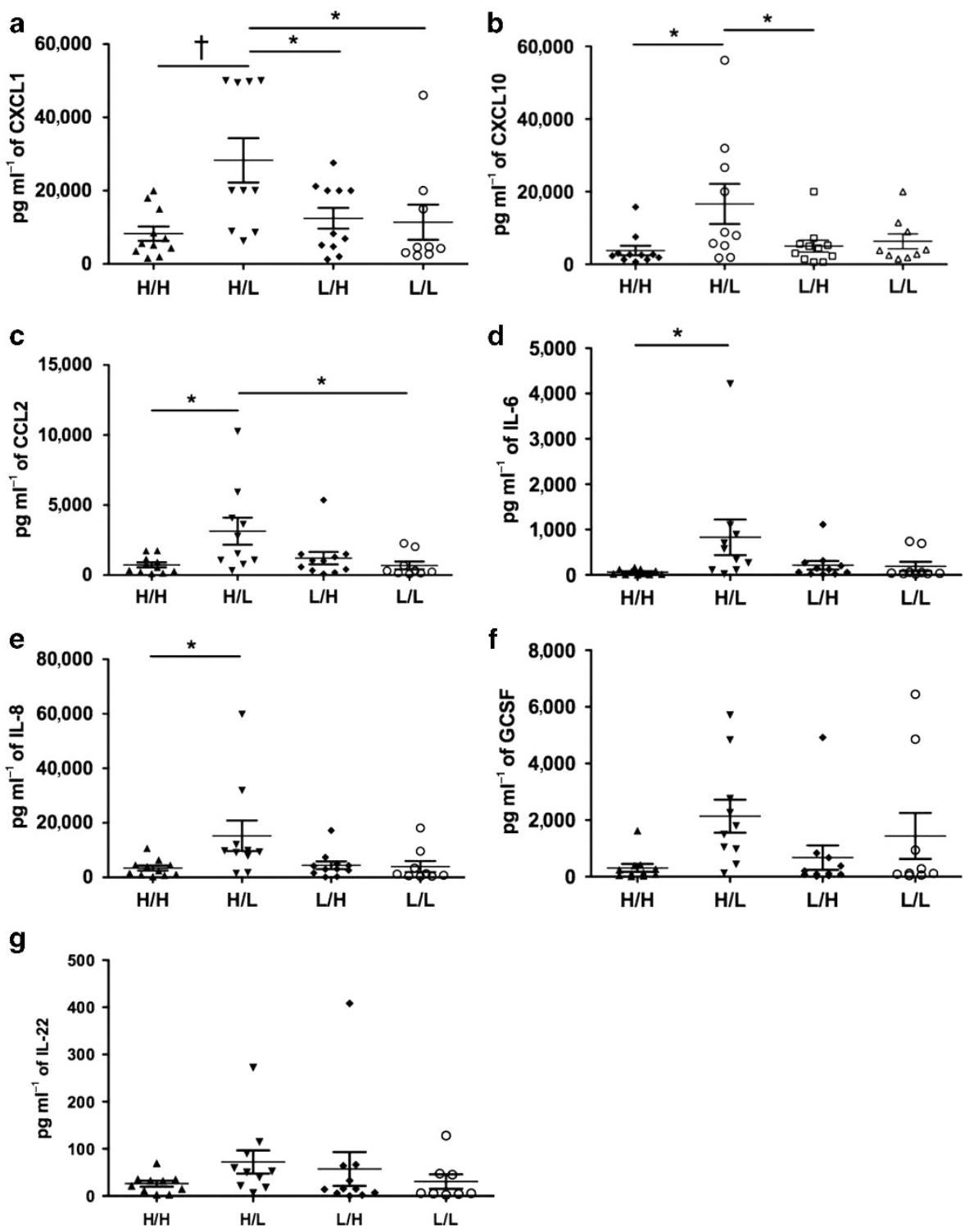

Figure 8 Severe asthmatics with high sputum neutrophilia and low eosinophilia have a distinct inflammatory profile. Asthmatics with high levels of neutrophils and low levels of eosinophils $(\mathrm{H} / \mathrm{L}, N=10)$ had increased sputum CXCL1 (a), CXCL10 (b), CCL2 (c), IL-6 (d), and IL-8 (e) when compared with those with high neutrophils and eosinophils $(\mathrm{H} / \mathrm{H}, N=11)$, with low neutrophils and high eosinophils $(\mathrm{L} / \mathrm{H}, N=11)$, and low levels of both cells $(\mathrm{L} / \mathrm{L}, N=9)$. G-CSF (f) and IL-22 (g) levels were not significantly different among the groups. Each point represents one patient. Mean \pm s.e.m.; ${ }^{\star} P<0.05$, ${ }^{\dagger} P<0.01$. G-CSF, granulocyte colony-stimulating factor.

directly addressed the causal relationship between allergic inflammation and $\mathrm{T}_{\mathrm{H}} 17$-induced allergic airway disease. The goal of this work was to determine whether allergic inflammation is directly related to AHR in a model of $\mathrm{T}_{\mathrm{H}} 17$-induced allergic airway disease. In the present study, two approaches were used to study the role of inflammation in the $\mathrm{T}_{\mathrm{H}} 17$ induced allergic airway disease in mice. First, TNF $\alpha$ or IL-17A was neutralized in $\mathrm{T}_{\mathrm{H}} 17$ cell transfer, OVA-challenged mice.

TNF $\propto$ is a potent pro-inflammatory cytokine with immunoregulatory activities and is principally produced by macrophages, whereas IL-17A is produced by T cells and is known to drive AHR in mice. ${ }^{20}$ Dysregulated TNF $\alpha$ responses have been implicated in several inflammatory conditions, including rheumatoid arthritis, ${ }^{21,22}$ Crohn's disease, ${ }^{23}$ Beçhet's disease, ${ }^{24}$ and $\mathrm{T}_{\mathrm{H}} 2$-dominant asthma. In this study, such treatment attenuated $\mathrm{T}_{\mathrm{H}} 17$ inflammatory disease in terms of airspace inflammation and cytokine production. However, neutralizing TNF $\alpha$ only rescued lung compliance, not AHR, and actually worsened mucus production in our in vivo studies. Further, anti-IL-17A treatment had less effect on inflammation, lung compliance, and AHR. In our previous work, deletion of IL-17RA inhibited $\mathrm{T}_{\mathrm{H}} 17$-induced disease to a greater extent than anti-IL-17A antibody did herein. ${ }^{4}$ It is possible that blocking IL-17A and/or multiple $\mathrm{T}_{\mathrm{H}} 17$-related cytokines (IL-17F and/or IL-25) may be required to have greater effects on allergic airway disease. 
Table 2 Correlations between pulmonary function and sputum cytokine levels in severe asthmatics

\begin{tabular}{lc}
\hline Comparison & Test statistics \\
\hline$H / H(N=11)$ & \\
IL-8 vs. FEV $1 \%$ predicted & $r_{\mathrm{s}}=-0.627(P=0.04)$ \\
IL-8 vs. FVC \% predicted & $r_{\mathrm{s}}=-0.664(P=0.03)$ \\
& \\
$H / L(N=10)$ & \\
CXCL1 vs. FEV $\%$ predicted & $r_{\mathrm{s}}=0.640(P=0.046)$ \\
IL-6 vs. FEV $\%$ predicted & $r_{\mathrm{s}}=0.766(P=0.01)$ \\
IL-6 vs. FEV $/$ FVC & $r_{\mathrm{s}}=0.733(P=0.02)$ \\
& \\
\hline$/ H(N=11)$ & \\
No significant correlations $(P>0.05)$ &
\end{tabular}

$L / L(N=9)$

CCL2 vs. FEV $1 \%$ predicted

$r_{\mathrm{s}}=-0.850(P=0.004)$

CCL2 vs. FVC \% predicted

$r_{\mathrm{s}}=-0.733(P=0.03)$

$\mathrm{FEV}_{1}$, forced expiratory volume in $1 \mathrm{~s}$; FVC, forced vital capacity; IL, interleukin. Data shown are Spearman's correlation coefficient values $\left(r_{s}\right)$ and were determined by a Spearman's correlation using SPSS statistical software. $P$-values are shown in parentheses.

The apparent disconnect between airspace inflammationdependent lung compliance and airspace inflammationindependent AHR is intriguing. These data suggest that the therapeutic potential of anti-TNF $\alpha$ may be limited to targeting airspace inflammation. Overall, lung compliance (which is rescued by anti-TNF $\alpha$ ) may be linked with airspace cellular inflammation, whereas AHR may be associated with tissue inflammation in this model of $\mathrm{T}_{\mathrm{H}} 17$-mediated allergic airway disease. Our data suggest that TNF $\alpha$ may be a critical cofactor for $\mathrm{T}_{\mathrm{H}}$ 17-driven inflammation, perhaps through its interaction with IL-17A and IL-17F (and/or additional $\mathrm{T}_{\mathrm{H}} 17$ products; IL-9, IL-21, or IL-22). This work illustrates that airspace inflammation and tissue inflammation are not equivalent in this model of allergic airway disease and reveals the complex relationship between lung function and cellular inflammation in severe asthma.

Secondly, neutrophils were depleted in $\mathrm{T}_{\mathrm{H}} 17$-induced allergic airway disease. There is increasing evidence that neutrophils are associated with severe asthma, although the functional relevance of these cells in disease progression remains unclear. In this study, neutrophil depletion had minimal effects on $\mathrm{T}_{\mathrm{H}} 17$-driven AHR and compliance, while it reduced mucus production. We did observe elevated lung production of neutrophil factors G-CSF, CXCL1, IL-6, and CXCL10. We believe this is because of the lack of feedback from neutrophils. As the lung is attempting to recruit neutrophils to the airspaces and neutrophils are depleted, more cytokines are produced to overcome this defect. Once again, lung compliance may be closely linked to airspace inflammation, whereas AHR may not.
The importance of each cell type in allergic inflammation and the development of AHR is not clear. One study showed that resolution of AHR and mucus hypersecretion correlated well with clearance of $\mathrm{T}_{\mathrm{H}} 2$ cells from the lung, but not eosinophils in the lung. ${ }^{25} \mathrm{~T}_{\mathrm{H}} 2$ cells were required for the development of allergic inflammation and the maintenance of an allergic response. ${ }^{25}$ Similarly, others found that reduction of neutrophils did not affect the development of later inflammatory changes in the airways or the development of AHR, suggesting the early and transient neutrophil response does not have a direct role in the development of allergen-induced AHR. ${ }^{26}$ However, another study revealed that AHR following allergic sensitization and challenge was neutrophil-dependent because it was abrogated in CXCR2-deficient mice and in wild-type mice receiving neutrophil depleting antibody, Gr- $1 .{ }^{27}$ Unfortunately, Gr-1 antibody also depletes macrophages and dendritic cells, which may explain this discrepancy. Depletion of antigen-presenting cells may attenuate AHR by blocking T-cell-dependent mechanisms independent of neutrophils.

This work reports the novel finding that severe asthma phenotypes segregated by inflammatory cell profile can be associated with an immunologically distinct cytokine profile detectable in sputum. Based on multiplex analyses for cytokines in the sputum, severe asthmatics with high levels of neutrophils and low levels of eosinophils display characteristics of neutrophil-mediated, $\mathrm{T}_{\mathrm{H}}$ 17-like disease. Furthermore, elevated cytokine levels in the sputum of high neutrophil, low eosinophil severe asthmatics did not predict worsened lung function. In fact, a number of cytokines significantly and directly correlated to $\mathrm{FEV}_{1} \%$ predicted, $\mathrm{FVC} \%$ predicted, and $\mathrm{FEV}_{1} / \mathrm{FVC}$ in this asthma endotype, suggesting that this severe asthma phenotype is driven by a different mechanism or perhaps a different cycle of the asthma inflammatory process. Conversely, sputum cytokine levels inversely correlated with lung function in the other severe asthma groups, further suggesting a different mechanism of disease within those phenotypes. Overall, these findings further define the immunopathology that underlies severe asthma and may help identify a target population of severe asthmatics, who have difficult to control disease, for a specific approach to therapy.

AHR is a defining clinical feature of asthma; however, the mechanisms underlying the development of AHR are still under investigation. Research has focused on understanding the effects of TNF $\alpha$, IL-13, IL-17A, and other cytokines on mediating immune responses in asthma. ${ }^{13,14,28-34}$ However, most therapeutic strategies in asthma that target the inflammatory processes have had variable success. Indeed, clinical studies using various $\mathrm{TNF} \alpha$ neutralizing antibodies showed no benefit or improvements in lung mechanics in asthmatics. ${ }^{35-38}$ A recent clinical study also shows brodalumab, a human antiIL-17RA monoclonal antibody, that blocks the activity of IL-17A, IL-17F, and IL-25 did not consistently lessen disease in patients with asthma. ${ }^{39}$ Based on our findings, these clinical studies may not have shown benefits from these anti-inflammatory therapies for two reasons. One reason is that inhibiting inflammation by limiting TNF $\alpha$ and IL-17A is not sufficient as 
it only limits airspace inflammation, while not completely impacting tissue inflammation or AHR and increasing mucus production. More importantly, we believe that these treatments were not found to be efficacious in clinical studies, as our results suggest that not all asthmatics may respond based on the inflammatory composition of their sputum. The results of this work suggest that inflammation might not be linked directly to physiology, and that disease phenotype of patients needs to be considered. In support of this, targeting of TNF $\alpha$ in severe, steroid-resistant asthmatics showed more promising efficacy. ${ }^{37}$

Current literature and these results also imply an inflammation-independent process, possibly related to direct effects on epithelial cells and the lung matrix. Epithelial and extracellular matrix changes may account for the elevation in mucus production and inconsistent change to AHR. Indeed, a study has shown that the IL-17A-induced changes in airway smooth muscle contraction alters AHR. ${ }^{20}$ Further, we recognized that IL-33 is also known to be sufficient and is required for severe allergic airway disease, ${ }^{40}$ and may also contribute to the sustained tissue inflammation, variable AHR, and increased mucus production in these studies.

Based on the apparent disconnect between airway inflammation, AHR, and lung compliance in neutrophil-dominant severe asthma, it is clear that both innate and adaptive immune response in the lung are likely contributing to different aspects of disease. The clinical significance of this disparate regulation of AHR and compliance is unclear. It is not surprising that lung stiffening may be mechanistically distinct from methacholine responsiveness, as changes in lung compliance in humans in either direction can be associated with decreased $\mathrm{FEV}_{1}$. A better understanding of these underlying immune mechanisms is required. It is likely that the $\mathrm{T}$-cell responses and/or the structural status of the airway, not necessarily inflammation, is important to AHR. Further, $\mathrm{T}_{\mathrm{H}} 17$-induced allergic airway disease is comprised of distinct inflammatory, mucus, and AHR mechanisms that are not necessarily driven by common pathways. These observations are likely critical in designing appropriate therapy for patients with severe asthma.

\section{METHODS}

Adoptive transfer model. Six- to eight-week-old female BALB/c SCID and C.DO11.10 OVA-specific TCR-transgenic mice (Jackson Laboratory, Bar Harbor, ME) were housed at the Children's Hospital of Pittsburgh in a pathogen-free environment. Experiments were approved by The University of Pittsburgh Institutional Animal Care and Use Committee. $\mathrm{CD} 4{ }^{+} \mathrm{CD} 62^{+}$naive T cells from the spleens of DO11.10 mice were cultured as previously reported. ${ }^{4}$ BALB/c SCID mice were challenged with $50 \mu \mathrm{g}$ OVA (Sigma-Aldrich, St Louis, MO) via oropharyngeal aspiration, and $1 \times 10^{6} \mathrm{~T}_{\mathrm{H}} 17$ cells were adoptively transferred by retro-orbital injection. Control mice received OVA challenges, but PBS retro-orbitally at time of cell transfer. Mice were treated with either $300 \mu \mathrm{g}$ of control IgG1, $100 \mu \mathrm{g}$ anti-TNF $\alpha$ antibody (CNTO 5048, Janssen R\&D, Spring House, PA), $300 \mu \mathrm{g}$ of anti-IL-17A antibody (CNTO 8096, Janssen R\&D), or $250 \mu \mathrm{g}$ of control rat IgG2a or murine Ly6G antibody, clone 1A8 (BioXCell, West Lebanon, NH), or $200 \mu \mathrm{l}$ of PBS via intraperitoneal injection.

Murine AHR and allergic airway disease measurements. AHR to methacholine challenge was done as previously described. ${ }^{41-43}$
Following these analyses, BAL fluid was collected and total cells were counted using a hemocytometer. Cytospin preparations of BAL cells were used for differential counting. Lung lobes were separated and processed as follows: flash frozen in liquid nitrogen for cytokine analysis by Lincoplex or gene expression analyses by real-time PCR (Life Technologies, Grand Island, NY) or inflation fixed with 10\% buffered formalin and paraffin embedded for histology. Inflammation and mucus production were assessed by hematoxylin and eosin and PAS staining, respectively, and scored by a pathologist who was blinded to the sample groups.

Human subjects. Sputum collection was completed on 41 subjects, ranging from age 9 to 64 years, participating in the Severe Asthma Research Program at The University of Pittsburgh. Subjects included severe asthmatics (as defined by the American Thoracic Society Workshop on Refractory Asthma ${ }^{18}$ ) who had sputum induction, or, if safety criteria were not met, a spontaneous sputum collected $(n=3)$. Samples were collected with approval from The University of Pittsburgh Institutional Review Board.

Sputum induction and processing. Sputum induction method was adopted from the Asthma Clinical Research Network method described in detail ${ }^{44}$. Briefly, after establishing a post-bronchodilator baseline (safety criterion of $\geqslant 60 \%$ ), subjects inhaled nebulized $3 \%$ buffered saline to produce induced sputum. Collections and pulmonary functions were done every $4 \mathrm{~min}$ for a maximum of 12 min. If subject $\mathrm{FEV}_{1}$ dropped below $80 \%$ of their post-bronchodilator $\mathrm{FEV}_{1}$, then induction was terminated for patient safety. Induced sputum was processed using equal amounts of $10 \%$ Sputolysin (Calbiochem, La Jolla, CA) immediately after collection. Sputum supernatant was obtained by centrifugation and cell cytospins were stained for differential count of leukocytes, bronchial epithelial, and squamous cells.

Cytokine analyses. Human sputum supernatant and murine lung homogenate samples were analyzed using custom Lincoplex multiplex kits according to manufacturer's instructions. IL-22 levels in human sputum supernatants were measured by enzyme-linked immunosorbent assay (R\&D Systems, Minneapolis, MN).

Statistical analyses. Data were analyzed using GraphPad Prism 5.0 (GraphPad Software, La Jolla, CA). Experiments involving two variables (AHR measurement, Lincoplex results, and BAL fluid differentials) were analyzed by two-way analysis of variance with a Bonferoni post hoc test. Data with one variable were analyzed using one-way analysis of variance with Tukey's post hoc test. Spearman's correlation analyses were conducted using SPSS 20 (IBM, Armonk, NY) where appropriate. Data shown are mean \pm s.e.m. A value of $P<0.05$ was considered to be statistically significant.

SUPPLEMENTARY MATERIAL is linked to the online version of the paper at http://www.nature.com/mi

\section{ACKNOWLEDGMENTS}

This work was supported by National Institute of Health/National Heart, Lung, and Blood Institute grants HL069174 (to S.E.W.), CTSI UL1 RR024153 (to S.E.W.), HL079142 (to J.K.K.), HL107380 (to J.F.A.), American Thoracic Society Unrestricted Research Grant Program (to J.F.A.), Janssen Research and Development (to M.M.E. and J.F.A.), and Children's Hospital of Pittsburgh of UPMC (to M.L.M.).

\section{DISCLOSURE}

The anti-TNF $\alpha$, anti-IL-17A, and control IgG1 antibodies used in these studies were provided by Janssen Research and Development who also supported a portion of this work (regarding these antibodies) via a research contract.

(c) 2014 Society for Mucosal Immunology 


\section{REFERENCES}

1. Holgate, S.T. \& Polosa, R. The mechanisms, diagnosis, and management of severe asthma in adults. Lancet 368, 780-793 (2006).

2. Bateman, E.D. et al. Can guideline-defined asthma control be achieved? The Gaining Optimal Asthma ControL study. Am. J. Respir. Crit. Care Med. 170, 836-844 (2004).

3. Bousquet, J. et al. Uniform definition of asthma severity, control, and exacerbations: document presented for the World Health Organization Consultation on Severe Asthma. J. Allergy Clin. Immunol. 126, 926-938 (2010).

4. McKinley, L. et al. TH17 cells mediate steroid-resistant airway inflammation and airway hyperresponsiveness in mice. J. Immunol. 181, 4089-4097 (2008).

5. Gibson, P.G., Simpson, J.L. \& Saltos, N. Heterogeneity of airway inflammation in persistent asthma : evidence of neutrophilic inflammation and increased sputum interleukin-8. Chest 119, 1329-1336 (2001).

6. Louis, R. et al. The relationship between airways inflammation and asthma severity. Am. J. Respir. Crit. Care Med. 161, 9-16 (2000).

7. Wenzel, S.E., Balzar, S., Cundall, M. \& Chu, H.W. Subepithelial basement membrane immunoreactivity for matrix metalloproteinase 9: association with asthma severity, neutrophilic inflammation, and wound repair. J. Allergy Clin. Immunol. 111, 1345-1352 (2003).

8. Green, R.H. et al. Analysis of induced sputum in adults with asthma: identification of subgroup with isolated sputum neutrophilia and poor response to inhaled corticosteroids. Thorax 57, 875-879 (2002).

9. Cox, G. Glucocorticoid treatment inhibits apoptosis in human neutrophils. Separation of survival and activation outcomes. J. Immunol. 154, 4719-4725 (1995).

10. Schleimer, R.P., Freeland, H.S., Peters, S.P., Brown, K.E. \& Derse, C.P. An assessment of the effects of glucocorticoids on degranulation, chemotaxis, binding to vascular endothelium and formation of leukotriene B4 by purified human neutrophils. J. Pharmacol. Exp. Ther. 250, 598-605 (1989).

11. Leung, D.Y., Spahn, J.D. \& Szefler, S.J. Steroid-unresponsive asthma. Semin. Respir. Crit. Care Med. 23, 387-398 (2002).

12. Bossley, C.J. et al. Pediatric severe asthma is characterized by eosinophilia and remodeling without $\mathrm{T}(\mathrm{H}) 2$ cytokines. J. Allergy Clin. Immunol. 129, 974-982. e13 (2012).

13. Howarth, P.H. et al. Tumour necrosis factor (TNFalpha) as a novel therapeutic target in symptomatic corticosteroid dependent asthma. Thorax 60, 1012-1018 (2005).

14. Berry, M.A. et al. Evidence of a role of tumor necrosis factor alpha in refractory asthma. N. Engl. J. Med. 354, 697-708 (2006).

15. Aujla, S.J. \& Alcorn, J.F. T(H)17 cells in asthma and inflammation. Biochim. Biophys. Acta. 1810, 1066-1079 (2011).

16. Evans, C.M., Kim, K., Tuvim, M.J. \& Dickey, B.F. Mucus hypersecretion in asthma: causes and effects. Curr. Opin. Pulm. Med. 15, 4-11 (2009).

17. Long, A.J. et al. Gob-5 contributes to goblet cell hyperplasia and modulates pulmonary tissue inflammation. Am. J. Respir. Cell Mol. Biol. 35, 357-365 (2006).

18. Proceedings of the ATS workshop on refractory asthma: current understanding, recommendations, and unanswered questions. American Thoracic Society. Am. J. Respir. Crit. Care Med. 162, 2341-2351 (2000).

19. Wenzel, S. Severe asthma: from characteristics to phenotypes to endotypes. Clin. Exp. Allergy 42, 650-658 (2012).

20. Kudo, M. et al. IL-17A produced by alphabeta T cells drives airway hyperresponsiveness in mice and enhances mouse and human airway smooth muscle contraction. Nat. Med. 18, 547-554 (2012).

21. Choy, E.H. \& Panayi, G.S. Cytokine pathways and joint inflammation in rheumatoid arthritis. N. Engl. J. Med. 344, 907-916 (2001).

22. Olsen, N.J. \& Stein, C.M. New drugs for rheumatoid arthritis. N. Engl. J. Med. 350, 2167-2179 (2004).
23. Owczarek, D., Cibor, D., Glowacki, M.K., Ciesla, A. \& Mach, P. TNF-alpha and soluble forms of TNF $1 / 2$ receptors in the serum of patients with Crohn's disease and ulcerative colitis. Pol. Arch. Med. Wewn. 122 (12), 616-623 (2012).

24. Mendoza-Pinto, C. et al. Etiopathogenesis of Behcet's disease. Autoimmun. Rev. 9, 241-245 (2010).

25. Kearley, J., Buckland, K.F., Mathie, S.A. \& Lloyd, C.M. Resolution of allergic inflammation and airway hyperreactivity is dependent upon disruption of the T1/ST2-IL-33 pathway. Am. J. Respir. Crit. Care Med. 179, 772-781 (2009).

26. Taube, C. et al. Inhibition of early airway neutrophilia does not affect development of airway hyperresponsiveness. Am. J. Respir. Cell Mol. Biol. 30, 837-843 (2004).

27. Wilson, R.H. et al. Allergic sensitization through the airway primes Th17dependent neutrophilia and airway hyperresponsiveness. Am. J. Respir. Crit. Care Med. 180, 720-730 (2009).

28. Brightling, C., Berry, M. \& Amrani, Y. Targeting TNF-alpha: a novel therapeutic approach for asthma. J. Allergy Clin. Immunol. 121, 5-10. quiz 11-2 (2008)

29. Lajoie, S. et al. Complement-mediated regulation of the IL-17A axis is a central genetic determinant of the severity of experimental allergic asthma. Nat. Immunol. 11, 928-935 (2010).

30. Grunig, G. et al. Requirement for IL-13 independently of IL-4 in experimental asthma. Science 282, 2261-2263 (1998).

31. Alcorn, J.F., Crowe, C.R. \& Kolls, J.K. TH17 cells in asthma and COPD. Annu. Rev. Physiol. 72, 495-516 (2010).

32. Wills-Karp, M. et al. Interleukin-13: central mediator of allergic asthma. Science 282, 2258-2261 (1998).

33. Souwer, Y., Szegedi, K., Kapsenberg, M.L. \& de Jong, E.C. IL-17 and IL-22 in atopic allergic disease. Curr. Opin. Immunol. 22, 821-826 (2010).

34. Russo, C. \& Polosa, R. TNF-alpha as a promising therapeutic target in chronic asthma: a lesson from rheumatoid arthritis. Clin. Sci. 109, 135-142 (2005).

35. Holgate, S.T. et al. Efficacy and safety of etanercept in moderate-to-severe asthma: a randomised, controlled trial. Eur. Respir. J. 37, 1352-1359 (2011).

36. Wenzel, S.E. et al. A randomized, double-blind, placebo-controlled study of tumor necrosis factor-alpha blockade in severe persistent asthma. Am. J. Respir. Crit. Care Med. 179, 549-558 (2009).

37. Taille, C. et al. Monoclonal anti-TNF-alpha antibodies for severe steroiddependent asthma: a case series. Open Respir. Med. J. 7, 21-25 (2013).

38. Morjaria, J.B. et al. The role of a soluble TNFalpha receptor fusion protein (etanercept) in corticosteroid refractory asthma: a double blind, randomised, placebo controlled trial. Thorax 63, 584-591 (2008).

39. Busse, W.W. et al. Randomized, double-blind, placebo-controlled study of Brodalumab, a human anti-IL-17 receptor monoclonal antibody, in moderate to severe asthma. Am. J. Respir. Crit. Care Med. 188, 1294-1302 (2013).

40. Louten, J. et al. Endogenous IL-33 enhances Th2 cytokine production and T-cell responses during allergic airway inflammation. Int. Immunol. $\mathbf{2 3}$, 307-315 (2011).

41. Bates, J.H. \& Irvin, C.G. Measuring lung function in mice: the phenotyping uncertainty principle. J. Appl. Physiol. 94, 1297-1306 (2003).

42. Alcorn, J.F. et al. Transforming growth factor-beta1 suppresses airway hyperresponsiveness in allergic airway disease. Am. J. Respir. Crit. Care Med. 176, 974-982 (2007).

43. Hantos, Z., Daroczy, B., Suki, B., Nagy, S. \& Fredberg, J.J. Input impedance and peripheral inhomogeneity of dog lungs. J. Appl. Physiol. 72, 168-178 (1992).

44. Hastie, A.T. et al. Analyses of asthma severity phenotypes and inflammatory proteins in subjects stratified by sputum granulocytes. J. Allergy Clin. Immunol. 125, 1028-1036. e13 (2010). 